\title{
Sexually transmitted diseases in children: human papillomavirus infection
}

\author{
J D Oriel
}

\section{An historical overview}

Recognition that anogenital warts in adults are predominantly a sexually transmitted disease has come only within the last 40 years. ${ }^{12}$ Throughout the last century the disease was attributed to poor hygiene or irritation from gonococcal and other discharges. Its viral aetiology was discovered early in the present century, but it was thought that there was only one human papillomavirus (HPV), which caused all types of wart, and that sexual contact was only one of many ways by which this virus could reach the anogenital epithelia. The modern concept of HPV infection has developed from clinical and virological research. Anogenital warts in adults are now regarded as a sexually transmitted disease; the epidemiology of subclinical HPV infections is less well established, but it is likely that these too are sexually transmitted. Molecular virology has shown that there are at least 60 HPV genotypes. HPV 1-4 are predominantly associated with skin warts of non-genital areas, HPV 6 and 11 with condylomata acuminata, papular warts and subclinical anogenital lesions and HPV 16, 18, and more rarely HPV $31,35,39$ and $41-45$ with dysplasia of the cervix, vulva, penis and anus.

Anogenital warts in children were mentioned only en passant in the early literature. The first case report in the English language, which described a 3 year old girl with gonorrhoea and multiple vulval condylomas, did not appear until $1940,{ }^{4}$ and between then and 1980 only 18 other cases were reported. ${ }^{5}$ In recent years there has been a marked increase in the number of cases published; since the disease is not difficult to diagnose, this may reflect a true increase in incidence, in parallel with the current epidemic of anogenital warts in adults. ${ }^{6}$ Suggestions that condylomata acuminata in children might be a sign of sexual abuse began to appear in the $1970 \mathrm{~s},{ }^{78}$ and its place in the natural history of the disease has been repeatedly discussed since then.

\section{Epidemiology}

There appear to be several ways in which HPV can reach a child's anogenital area and cause warts: (1) from the mother before delivery, (2) from the mother during delivery, (3) through close but non-sexual contact with a member of the family circle, (4) through one or more sexual encounters and (5) through the transfer of HPV from warts on the child's own hands or the hands of other children or adults. $^{89}$ Very little is known about the epidemiology of subclinical or latent anogenital HPV in children.

Tang et $a l^{10}$ reported the appearance of congenital condylomata acuminata in a premature infant; presumably infection was by an ascending infection of the mother's genital tract or, conceivably, through maternal viraemia. Hajek ${ }^{11}$ reported the case of a boy whose mother had genital warts at the time of delivery; at the age of six months he developed penile warts, and at the age of 18 months laryngeal papillomas. Cohen et al ${ }^{12}$ studied 73 children with anogenital warts. Seven of these had warts at birth, according to their parents; one of these, whose mother was known to have genital warts, was delivered by caesarian section. These and other cases indicate that anogenital warts in children may be due to infection from their mothers during, or even before, delivery. This idea is supported by a report that analysis by dot-blot hybridisation of 70 foreskins from infants undergoing routine circumcision showed that two contained sequences of HPV 16 and one of HPV 6; whether the infection occurred during delivery or in utero could not be determined..$^{13}$ Juvenile laryngeal papillomas are also linked to maternal genital warts; they do not present before three or four months of age and almost half are not diagnosed before the age of two years, ${ }^{14}$ which suggests a long incubation period for these lesions. The uncertain incubation period of HPV infection adds to the difficulty of establishing a source for anogenital warts in children. $^{12}$

The evidence that children can contract anogenital warts through close non-sexual contact with a family member is anecdotal. A child investigated by Rock et $a l^{15}$ may have been infected by bathing with a female relative who had genital warts. Gibson et $a l^{9}$ had a similar case. These authors had also seen a child with genital warts who had anal stenosis which was being dilated by the mother, who was also reported to have warts. Jochmus-Kudielka et al tested samples of human sera by the Western blot technique for the presence of antibodies to HPV16 proteins E4 and E7. Approximately one third of children under the age of 10 years had anti E4-positive sera. The authors suggest that in some instances infection with HPV16 may occur early in life, most likely by asexual transmission or during delivery. ${ }^{16}$

For the last decade it has been stated, particularly by workers in the USA, that most cases of anogenital warts in children are due to sexual abuse..$^{17-19}$ In a recent study HermanGiddes $e t a l^{20}$ found that 10 of 11 girls with
University College and Middlesex School of Medicine, London WC1E 6BT, UK 
genital warts had historical and/or physical evidence of sexual abuse; three of the girls were infected by Neisseria gonorrhoeae and one by Trichomonas vaginalis, and the authors suggest that all, or almost all, genital warts in children are sexually transmitted. This opinion is not unanimous. Neinstein $e a^{21}$ reviewed 37 cases of anogenital warts in both sexes, of which only nine were thought to be due to abuse-admittedly, in ten cases there was no information on the presumed means of infection. Shelton et $a l^{22}$ had seen 26 prepubertal cases, but attributed only eight to abuse. Finally, in recent study ${ }^{12} 73$ children with anogenital warts were carefully evaluated for sexual abuse, but in 66 there was no evidence that such abuse had occurred. Hanson $e t a l^{23}$ have pointed out that in some children with anogenital warts more than one potential causal factor may be present; sexual abuse may have occurred in some cases where vertical transmission might have been suspected.

Autoinoculation of HPV, or inoculation from other children during play, has been suggested as a possible cause of some cases of anogenital warts. One convincing case has been published in which a five year old boy presented with multiple anal warts and three common warts on one hand; HPV 2 was identified in lesions at both sites. ${ }^{24}$ Other workers have thought that the transmission of hand warts to children with resulting anogenital warts is very unlikely. ${ }^{25}$

Since the typing of HPV has shown that the viral types are to a large extent site-specific, it was hoped that hybridisation techniques would clarify the epidemiology of anogenital warts in children. This has not happened. Rock et $a l^{15}$ examined specimens from five children and found sequences of HPV 6/11 in four and of HPV 16 in one. These "genital" types are those which are present in the majority of adult anogenital warts. What of the "skin" types, HPV 1-4? In $1980 \mathrm{Krzyzek}$ et al ${ }^{26}$ had reported several different HPVs, including some "skin" types, in anogenital wart tissue. These results have been criticised on methodological grounds, ${ }^{27}$ but HPV 2 has been found in a young boy's anal warts, ${ }^{24}$ and it has been reported that $25 \%$ of anogenital warts in children contain HPV $2 .^{28}$ Padel et $a l^{29}$ examined 17 biopsy specimens from children; ten contained "genital" types HPV 6/11, and six contained "skin" types, HPV 1 or 3 . The virus type bore no relationship to the site or appearance of the warts, but "skin" types were commoner in children more than four years of age, in those with a relative with skin warts and in children with warts elsewhere; there was no suspicion of abuse in children in this group. On the other hand "genital" types were commoner in children less than three years of age, who had no relatives with warts and who had no warts elsewhere. But to equate anogenital warts containing "genital" HPV types with sexual abuse is unjustified, because in half the children in this group there was no suspicion or evidence that they had been abused.

Cohen et al ${ }^{12}$ examined 73 children with anogenital warts and took tissue samples from
43; HPV 6/11 was present in 27 specimens, HPV 2 in six and HPV 1,16 and 18 in one specimen each. Warts were identified in 35 $(48 \%)$ of parents of the 73 children, 25 on the extremities and 12 on the anogenital area. Finally, Gibson et $a l^{9}$ examined specimens from 25 children with anogenital warts, ten of whom were thought to have been the victims of sexual abuse. HPV 6/11 was found in 20, HPV 18 in one and HPV 2 in one. In three cases genital wart material was available from one of the parents, and in each case the HPV types from parent and child were identical.

What are we to make of these data? It seems clear that since there are several routes of transmission for HPV the presence of anogenital warts in a child is not a reliable indicator that sexual abuse has occurred. Identification of the viral type present may be useful, but this result must in each case be considered together with the clinical and social findings. The importance of skilled, level-headed and unbiased investigation of the family situation needs no emphasis.

\section{Clinical presentation}

The majority of anogenital warts in children affect vulval and perianal areas; penile warts in children are very unusual, although they have been described. ${ }^{30}$ There may occasionally be associated warty lesions on the body skin or in the mouth. ${ }^{42}$ As in adults, three types of HPV-associated lesion can be identified, condylomatous, papular and flat (subclinical). Classical condylomata acuminata are soft, fleshy and vascular tumours of widely variable size and shape; they may coalesce to form large masses (fig 1). With magnification, various capillary patterns have been identified: "hairpin, corkscrew, hayfork or fan-like". ${ }^{31}$ In girls these condylomas usually affect moist areas such as the vaginal introitus, urethral, perineal and perianal areas, but they may affect any anogenital site. Vulval and urethral condylomas may become very large. ${ }^{32} 33$ In boys, condylomas most often affect perianal and perigenital areas. It has been suggested that the presence of lesions which are perianal, rather than being on the buttocks or buttock creases, strengthen the possibility of sexual abuse. ${ }^{34}$ In adults, perianal condylomas often affect the anal canal as well; whether this also occurs in children is unclear at present.

Papular (sessile) warts, (fig 2) are most common on fully keratinised parts of the anogenital epithelium. They are usually multiple and are raised, 1-3 $\mathrm{mm}$ in diameter, and with a fairly smooth surface. Flat warts (subclinical wart virus infection) can be identified with magnification after the application of $5 \%$ acetic acid. They may occur alone or in association with other types of wart, are of very variable size and shape, and are characteristically "shiny white" in colour. Information about the occurrence of these lesions in children is scanty, but they have been described. ${ }^{12}$ In adults colposcopic, cytological and histological abnormalities of the cervix uteri are common in women with vulval warts; whether this occurs in children is not known. 


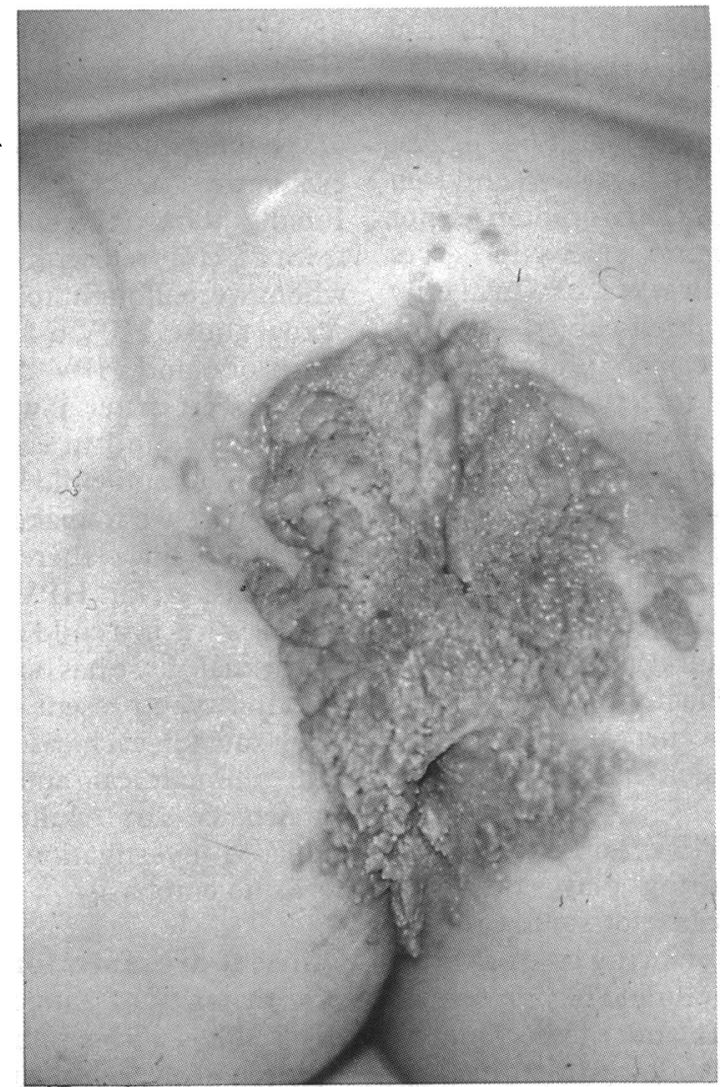

Fig 1 Condylomata acuminata.

\section{Diagnostic methods}

The diagnosis of anogenital warts in children is usually made on clinical grounds, but in view of possible medicolegal developments this should be supported by histology in all cases. The differential diagnosis includes molluscum contagiosum, skin tags, naevi, neurofibromas and other benign tumours. Condylomata lata are

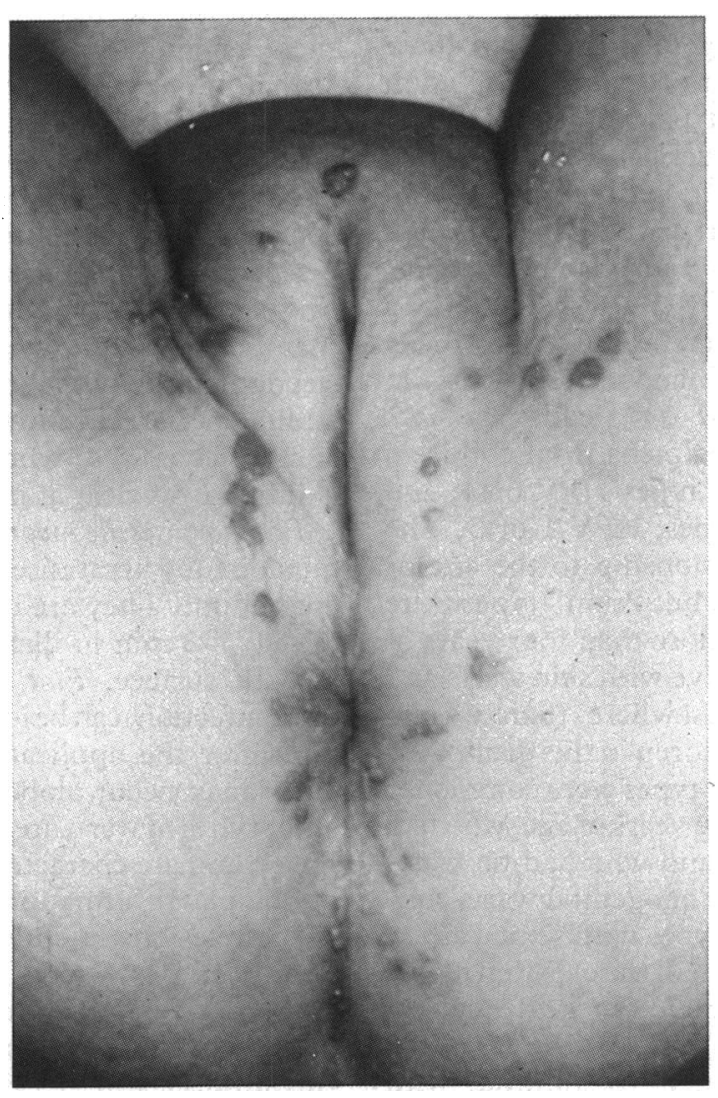

Fig 2 Papular warts. rare these days, but should always be excluded by appropriate laboratory tests for syphilis.

Clinical examination is poor at predicting the HPV type present. ${ }^{29}$ The identification of this will require a virological technique which accurately distinguishes the genotypes, and this means that probes for both "skin" and "genital" types are used. These are at present not available at all centres, but if only "genital" probes are used lesions containing "skin" types will be reported as "negative", and this could lead to errors in interpretation. Examination of the child's parents for evidence of clinical or subclinical HPV infection may provide useful information, but it may be difficult to arrange. Finally, as any anogenital wart in a child may be due to sexual abuse it is desirable to perform screening tests for other sexually transmitted diseases in every case.

\section{Treatment and follow up}

The treatment modalities available for children with anogenital warts are the same as those for adults - the application of a cytotoxic agent or mechanical destruction of the tumours. No controlled treatment trials have been made in children, so therapy becomes a matter of personal preference based on experience. Some general observations may, however, be made. Podophyllin should be used cautiously in children, because of reactions involving the surrounding skin, but the careful application of a $10 \%$ solution in spirit may be useful for small non-keratinised lesions. Large condylomas should not be treated with podophyllin because of its toxic potential if absorbed. If podophyllin therapy is unsuccessful or inappropriate a surgical procedure will be necessary; this will require a local or (more probably for children) a general anaesthetic. Carbon dioxide laser therapy is the optimal treatment, particularly for large condylomas, but for small papillomas electrodesiccation is quite satisfactory. Opinions are divided on whether or how subclinical HPV in adults should be treated, and this problem in children has not as yet been addressed.

The post-treatment surveillance of children with anogenital warts is difficult to decide in the absence of any knowledge of the long term effects of the disease. If sexual abuse is proved, close follow up of the family is obviously necessary. In all cases, however, surveillance for at least six months after treatment is desirable in order to detect recurrent lesions. It has been suggested that a child infected with a potentially oncogenic viral type (such as HPV 16) should be followed with especial care, particularly after puberty, for anogenital neoplasia. ${ }^{35}$ Such a prolonged period of posttreatment surveillance is psychologically undesirable, and its benefits are at present unknown.

\section{Future developments}

There is a real need for more knowledge about anogenital HPV infection in children. The vexed question of sexual abuse will eventually 
be resolved when more cases have been fully evaluated clinically, virologically and socially, and it may then be possible to furnish further guidelines to help the clinician to decide whether the child is in need of care and protection. ${ }^{14}$

Virtually nothing is known of the long term history of these children. Will they shed virus at some point in the future and infect their partners when they become sexually active? Will latent HPV infection persist despite apparently successful treatment, and is there a real possibility that vulval or perianal intraepithelial neoplasia may develop in the future? If there is such a possibility, is it greater in those infected with so-called "high risk" types such as HPV 16? These are important problems, and their solution will require long term studies of the epidemiology, virology and sequelae of this disease, which was once rare but is now regrettably becoming commoner.

1 Barrett TJ, Silbar JD, McGinleyं JP. Genital warts-a venereal disease. JAMA 1954;154:333-4.

2 Oriel JD. Natural history of genital warts. Br J Venereal Dis 1971;467:1-13.

3 Stanley M. Genital papillomaviruses, polymerase chain reaction and cervical cancer. Genitourin Med 1990;66: 415-7.

4 Goldman L, Clarke GE. Infectious papilloma (so-called condyloma acuminatum) with genital, perineal and lip
lesions in a three year old child. Urol Cutan Rev 1940; lesions in

5 Stumpf PG. Increasing occurrence of condylomata acuminata in premenarchal children. Obstet Gynecol 1980 56:262-4.

6 Oriel JD. Genital papillomavirus infections-clinical manifestations. In: Oriel JD, Harris JRW eds. Sexually Transmitted Diseases 3. Edinburgh: Churchill Livingstone 1986:127-46.

7 Seidel J, Zonana J, Totten E. Condylomata acuminata as a sign of sexual abuse in children. $J$ Pediatr 1979;95:553-4.

8 de Jong AR, Weiss JC, Brent RL. Condylomata acuminata in children. Am J Dis Child 1982;136:704-6.

9 Gibson PE, Gardner SD, Best SJ. Human papillomavirus types in anogenital warts of children. J Med Virol 1990; types in anoge

10 Tang CK, Shermeta DW, Wood C. Congenital condylomata acuminata. Am J Obstet Gynecol 1978;131:912-3.

11 Hajek EF. Contribution to the etiology of laryngeal papilloma in children. J Laryngol Otol 1956;70:166-8.

12 Cohen BA, Honig P, Androphy E. Anogenital warts in children. Arch Dermatol 1990;126:1575-80.

13 Roman A, Fife F. Human papillomavirus DNA associated with foreskins of normal newborns. J Infect Dis 1986 153:855-61.

14 Bennett RS, Powell KR. Human papillomaviruses: association between laryngeal papillomas and genital warts. tion between laryngeal papillom
Pediatr Infect Dis 1987;6:229-32.

15 Rock B, Naghashfar Z, Barnett N, Buscema J, Woodruff JD, Shah K. Genital tract papillomavirus infection in children. Arch Dermatol 1986;122:1129-32.

16 Jochmus-Kudielka I, Schneider A, Braun R, et al. Antibodies against the human papillomavirus type 16 early proteins in human sera: correlation of anti-E7 reactivity with cervical cancer. J Nat Cancer Inst 1989;81:1698-709.

17 American Academy of Dermatology: Task Force on Pediatric Dermatology. Genital warts and sexual abuse in children. J Am Acad Dermatol 1984;11:529-30.

18 Rock B. Condylomata acuminata in the evaluation of child sexual abuse. Arch Dermatol 1987;123:1266.

19 Schachner L, Hankin DE. Assessing child abuse in childhood condylomata acuminatum. J Am Acad Dermatol 1985;12:157-60.

20 Herman-Giddens ME, Gutman LT, Berson NL. Association of coexisting vaginal infections and multiple abusers in female children with genital warts. Sex Transm Dis 1988;15:63-7.

21 Neinstein LS, Goldenring J, Carpenter S. Nonsexual transmission of sexually transmitted diseases: an infrequent occurrence. Pediatrics 1984;74:67-76.

22 Shelton TB, Jerkins GR, Noe HN. Condylomata acuminata in the pediatric patient. $J$ Urol 1986;135:548-9.

23 Hanson RM, Glasson M, McCrossin I, Rogers M, Rose B, Thompson C. Anogenital warts in childhood. Child Abus Thompson C. Anogenital warts

24 Fleming KA, Venning V, Evans M. DNA typing of genital warts and a diagnosis of sexual abuse of children. Lancet 1987;ii:454.

25 Davis AJ, Emans SDJ. Human papillomavirus infection in the pediatric and adolescent patient. $J$ Pediatr $1989 ; 115$ : $1-9$.

26 Krzyzek RA, Watts SL, Anderson DL, Faras AJ, Pass F. Anogenital warts contain several distinct species of human papillomavirus. J Virol 1980;36:236-44.

27 Goldenring JM. Condylomata acuminata in the evaluation of child sexual abuse. Arch Dermatol 1987;123:1265-6.

28 Androphy EJ. Human papillomavirus: current concepts. Arch Dermatol 1989;125:683-5.

29 Padel AF, Venning VA, Evans MF, Quantril L, Fleming KA. Human papillomaviruses in anogenital warts in children: typing by in situ hybridisation. BMJ 1990; 300:1491-4.

30 Kumar B, Gupta R, Sharma SC. Penile condylomata acuminata in a male child: a case report. Genitourin Med 1990;66:226-7.

31 von Krogh G. In: van Krogh G, Rylander E eds. GPVI (Genitoanal Papillomavirus Infection). Karlstad, Conpharm AB 1989:81-90.

32 Patel R, Groff DB. Condylomata acuminata in childhood. Pediatrics 1972;50:152-3.

33 Zamora S, Baumgartner G, Shaw $M$. Condyloma acuminatum in a $21 / 2$ year old girl. $J$ Urol 1983;129:145-6.

34 Goldenring JR. Warts and diagnosis of sexual abuse. Lancet 1987;ii:1018-9.

35 Bender ME. New concepts of condyloma acuminatum in children. Arch Dermatol 1986;122:1121-4. 